\title{
THESIS
}

\section{ATTITUDES OF HETEROSEXUAL ASSISTED LIVING RESIDENTS TOWARD GAY AND LESBIAN PEERS}

\author{
Submitted by \\ Weston Donaldson \\ Department of Psychology \\ In partial fulfillment of the requirements \\ For the Degree of Master of Science \\ Colorado State University \\ Fort Collins, Colorado
}

Spring 2012

Master's Committee:

Advisor: Tammi Vacha-Haase

James Banning

Justin Lehmiller 
Copyright by Weston Verlaine Donaldson 2012

All Rights Reserved 


\section{ABSTRACT \\ ATTITUDES OF HETEROSEXUAL ASSISTED LIVING RESIDENTS TOWARD GAY AND LESBIAN PEERS}

Sexual minorities in post-retirement care facilities fear discrimination and suboptimal care due to homophobia and heteronormative policies. This qualitative study explored the attitudes of 13 heterosexual assisted facility residents toward gay and lesbian peers in their facility. Although most participants reported that they were comfortable talking about homosexuality, the feelings, beliefs, and behaviors toward gay and lesbian residents that they described ranged from favorable, to ambivalent, to unfavorable. Results seemed to indicate that heterosexual residents still view sexual minorities as "others" who are unlikely to inhabit the same spaces they do. Recommendations for further research are provided in order to ameliorate the conditions of aged care facilities for all residents, including sexual minorities. 


\section{TABLE OF CONTENTS}

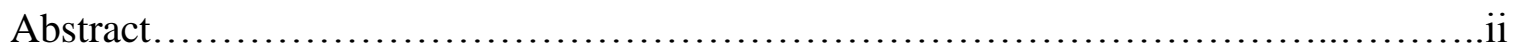

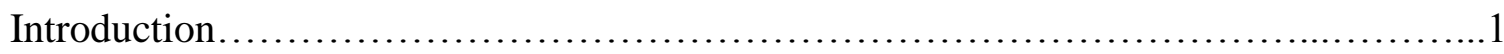

Older LGB Adults and Post-Retirement Care Services..........................2

Heteronormative Aspects of Assisted Living Facilities........................................

Heterosexual Attitudes Toward LGB Individuals..............................5

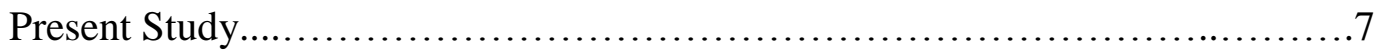

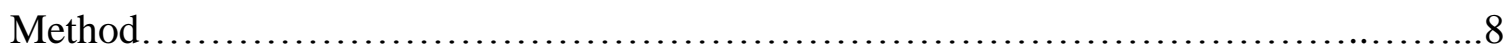

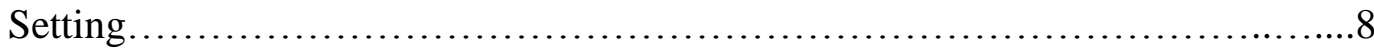

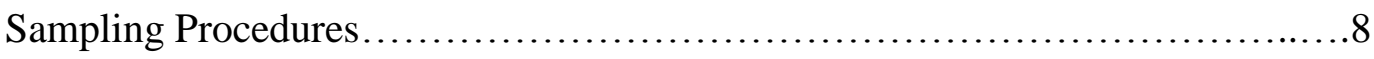

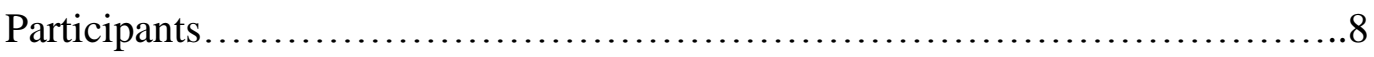

Measures................................................................ 10

Procedures.............................................................. 11

Qualitative Data Analysis...............................................13

Trustworthiness.........................................................

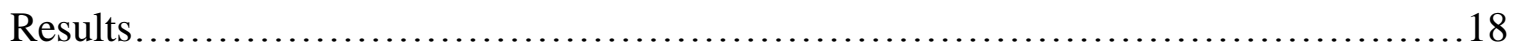

Master Themes and Subthemes...........................................18

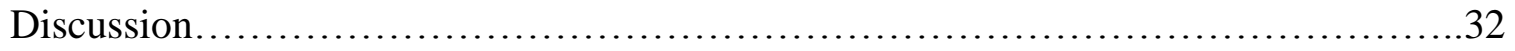




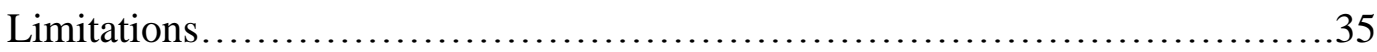

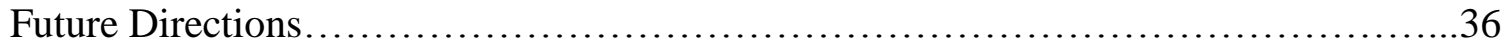

Conclusions........................................................ 37

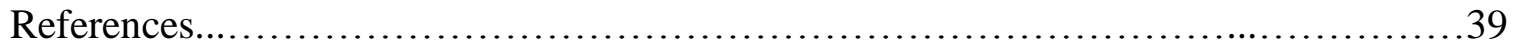

Appendix A............................................................... 46 


\section{LIST OF TABLES}

Table 1: Demographic Information of Interviewed ALF Residents....................

Table 2: Themes and Subthemes for Heterosexual ALF Residents' Attitudes Toward

Gay/Lesbian Peers........................................................19 


\section{Introduction}

Over the last four decades, the scholarship focusing on the lives of lesbian, gay, and bisexual (LGB) individuals has generally targeted younger populations, and clinical issues and health concerns have primarily been addressed in relation to HIV/AIDS (Hash \& Cramer, 2003). Even today, the majority of aging and LGB-focused research continues to disregard late life issues for sexual minorities, leading older LGB adults to be referred to as an "invisible population," (Butler, 2004; Hash \& Cramer, 2003; Hughes, 2007). However, older LGB adults will continue to become increasingly more visible in the general population. Current estimates predict that one in five people in the United States will be aged 65 or older in the year 2030 (Administration on Aging, 2000), meaning that there could be as many as two to seven million older LGB adults living in the US (Grant et al., 2010).

The present study approached the unique needs of gay and lesbian older adults in post-retirement care facilities by examining the attitudes of heterosexual assisted living facility (ALF) residents toward their gay and lesbian peers. The rationale for this study is derived from past research indicating that older LGB adults face many obstacles in accessing LGB-affirmative social services, health care, and housing (Addis, Davies, MacBride-Stewart, \& Shepherd, 2009). This is largely due to heteronormative and homophobic policies and attitudes that exist in greater society. Given these challenges, understanding how heterosexual ALF residents feel and behave toward their gay and 
lesbian peers may be an important part of understanding the environment inhabited by gay and lesbian residents, and is a step toward the vision of making assisted living facilities more welcoming and affirming to sexual minorities.

\section{Older LGB Adults and Post-Retirement Care Services}

Research on older LGB adults has identified their concerns surrounding health care, housing, and long-term care (Smith, McCaslin, Chang, Martinez, \& McGrew, 2010; Stein, Beckerman, \& Sherman, 2010; Quam \& Whitford, 1992). These concerns underscore the relevance of past and present discrimination to older gay and lesbian people, the invisibility of that population, and the need for social services that welcome sexual minorities (Brotman, Ryan, \& Cormier, 2003).

As is common with advancing age, older LGB people may find that they require services provided in ALFs and long-term care (LTC) facilities because they have increased difficulty taking care of their daily needs. Many older LGB adults have indicated that they would prefer LGB-friendly or LGB-specific housing facilities (Grant et al., 2010; Hamburger, 1997; Stein, Beckerman, \& Sherman, 2010); however, such facilities are sparse and difficult to locate, resulting in many individuals entering the facilities and communities that are geographically or economically available to them (Grant et al., 2010).

Unlike their heterosexual peers, older LGB adults encounter some unique issues in LTC and ALF settings (Shankle, Maxwell, Katzman, \& Landers, 2003). When entering a facility, LGB residents who have been "out" for a large portion of their lives may feel the need to go "back in the closet" for fear of being mistreated and denied care (Brotman, Ryan, \& Cormier, 2003; Grant et al., 2010; Johnson, Jackson, Arnette, \& 
Koffman, 2005; National Senior Citizens Law Center (NSCLC), 2011; Quam \& Whitford, 1992; Shankle et al., 2003; Stein, Beckerman, \& Sherman, 2010). This is concerning, since non-disclosure of sexual orientation has been_negatively associated with impact the quality of health care provided (Stein \& Bonuck, 2001; see Dean et al, 2000 , for an extensive discussion).

There is evidence that older LGB adults anticipate discrimination in postretirement care settings (Jackson, Johnson, \& Roberts, 2008; Quam \& Whitford, 1992). The majority of older gay and lesbian adults indicate that they fear discrimination in care facilities, with approximately one-third saying they are willing to hide their sexual orientation as a result (Johnson et al., 2005; Smith et al., 2010). Another significant concern is not being able to remain with their partner after entering an ALF or LTC facility (Smith et al., 2010).

Research has shown that the fears of older LGB adults are justified (Cahill et al., 2000; Cook-Daniels, 1997; Hash \& Cramer, 2005). Documented discrimination in LTC settings has included verbal or physical harassment by residents and facility staff, as well as discriminatory admission and discharge policies (Johnson et al, 2005; NSCLC, 2011). If partnered, they may experience lack of support and the misunderstanding of peers when a partner visits (Hash \& Cramer, 2005). These fears may partly be due to their lived experience of victimization throughout their lives based on their sexual orientation. Indeed, two-thirds of older LGB respondents surveyed reported encountering verbal abuse, one quarter reported threats of violence, and 16\% reported actual physical attacks during their lifetime (D’Augelli \& Grossman, 2001). 


\section{Heteronormative Aspects of Assisted Living Facilities}

Even if they do not experience overt discriminatory behavior, many LGB older adults and their caregivers face heteronormative and homophobic policies in care facilities (Hash \& Cramer, 2005; Tolley \& Ranzijn, 2006). The term "heteronormativity" originated in one of the seminal works of early Queer Theory by Warner (1991), and refers to the attitudes, systems, and practices that uphold heterosexual privilege and promote heterosexuality as the norm with which sexual identities are compared (Tolley \& Ranzijn, 2006). Homophobia refers to "feeling[s] or actions based on hatred, aversion or fear of same-sex attraction and sexual behavior among lesbian, gay or bisexual people" (Grant et al., 2010, p. 13).

Homophobic attitudes and heteronormative assumptions, both on an individual and institutional level, maintain status differences between heterosexuals and nonheterosexuals, and they are directly related to many of the fears and challenges older LGB adults face in post-retirement care facilities (Stein, Beckerman, \& Sherman, 2010). Even if individuals living with and serving older LGB adults are not overtly homophobic, if at all, they are likely heteronormative in that they rely on the default assumption that the individuals they serve are heterosexual (Elia, 2003; Jackson, 2006). As a result, staff or fellow residents may inquire about their "spouse" or grandchildren, which signifies a lack of awareness of gay and lesbian individuals and the ways they might differ from heterosexual peers. Furthermore, caregiving partners may face limited access to their loved one, or be denied access altogether, because of facility policies as well as health care regulations and limitations (Grant et al., 2010). Some caregivers of LGB older adults have experienced hostility in care facilities, whereas others anticipate it and prepare 
accordingly, perhaps by hiding the nature of their relationship or drafting advance directives (Hash \& Cramer, 2005).

Because of the heteronormative and homophobic attitudes, policies, and behaviors they face, older LGB people are at greater risk for being marginalized in a care facility, whether by staff or other residents (Shankle et al., 2003). This may result in sexual minority residents feeling socially isolated and lonely, which are conditions associated with poorer physical health, mental health, and well-being (Cacioppo, Hughes, Waite, Hawkley, \& Trusted, 2006; Cornwell \& Waite, 2009; Thompson \& Heller, 1990).

\section{Heterosexual Attitudes Toward LGB Individuals}

Attitudes are conventionally described as evaluations of an entity of some kind, ranging from unfavorable to favorable (Eagly \& Chaiken, 1993). Furthermore, an assessment of attitudes must consider cognitive, affective, and behavioral elements that are associated with attitude formation and change. It must be noted that attitudes are conceptualized as being separate from but interacting with feelings, thoughts, and behaviors (Albarracin, Zanna, Johnson, \& Kumkale, 2005), and it is from this perspective that the present study approaches the attitudes of the participants.

Existing research exploring the attitudes of heterosexual individuals toward LGB individuals has tended to be quantitative, and has targeted younger or undifferentiated populations. Overall, heterosexual men have been shown to express more negative attitudes toward lesbians and gay men than heterosexual women, and attitudes are generally more negative toward gay men than toward lesbians (Herek, 1988). Over the past three decades, prejudicial attitudes toward lesbians and gay men have become less 
negative, yet recent estimates of homophobic attitudes still range from 49 to 57 percent (Herek, 2007).

Examples of studies on attitudes toward gay men and lesbians have focused on college students (Korfhage, 2006; Mohipp \& Morry, 2004; Newman, Dannenfelser, \& Benishek, 2002; Whitley, 2002), attitudes of college students toward gay male couples who adopt children (McLeod, Crawford, \& Zechmeister, 1999), attitudes of staff and administrators toward gay and lesbian patients with intellectual disabilities (Abbott and Howarth, 2007), and attitudes of heterosexual women toward lesbians (Wilkinson, 2006). Results of these studies consistently demonstrated that factors such as stereotypes, previous contact with gay men and lesbians, religiosity, gender, and gender ideology were significant predictors of attitudes toward lesbians and gay men.

Even today, there is a paucity of research on attitudes of heterosexuals toward older gay men and lesbians. Some existing studies have looked at stereotypes of older lesbians and gay men (Wright \& Canetto, 2009) and LTC staff perceptions of same-sex sexual behavior (Hinrichs \& Vacha-Haase, 2010). Asta (2008) explored the attitudes of heterosexual LTC and ALF residents toward gay and lesbian peers. Results from the study showed that residents' level of previous interaction with sexual minorities influenced their awareness of and attitudes toward gay men and lesbians. Religion was also identified as a factor influencing the attitudes of the participants. Residents were generally uncomfortable when discussing their attitudes toward homosexuality and samesex relationships, and they emphasized the negative social implications for being gay or lesbian such as marginalization and changes in family structure. 
Although Asta (2008) identified important themes in the attitudes of heterosexual older adults in LTC and ALFs toward their gay and lesbian peers, little is known about the way these factors directly influence residents' thoughts, feelings, and behaviors toward gay and lesbian residents in their facilities. Understanding this would be useful in knowing what could be done to help ALF residents become more comfortable and affirming to gay and lesbian peers in their facilities.

\section{Present Study}

The purpose of the present study was to understand how heterosexual ALF residents might feel and act toward sexual minorities in their facilities, and to explore the role of previously identified factors in attitudes toward gay men and lesbians. The following research questions guided the inquiry of this study:

1. How do heterosexual assisted living residents react to the idea of gay men and lesbians in their facility?

2. What is the role of previously identified factors (knowledge of and interaction with gay men and lesbians, and religion) in their feelings toward gay men and lesbians in their facility?

For this study, Interpretative Phenomenological Analysis (IPA) was selected as an appropriate method to explore this question. Like other phenomenological approaches, IPA focuses on exploring and describing the experiences of participants through examining rich descriptions of those experiences. However, using an interpretative approach to data analysis accepts that the researcher can never fully access the full context and experience of participants, and that the researcher cannot help but interpret data through the lens of her or his own experience and context (Willig, 2001). 


\section{Method}

\section{Setting}

The research was conducted in an ALF located in northern Colorado. The facility houses approximately 70 residents at full capacity, and tends to serve low-income older adults in need of assisted living services. Unlike the previous related study (Asta, 2008), which examined attitudes of both LTC and ALF residents, the present study was focused exclusively on ALF residents. Although the answers to the research questions for both settings might be similar, the researchers chose to focus on the ALF context to have greater clarity of the experience of individuals in that type of facility.

\section{Sampling Procedures}

Participants were selected using purposive sampling, meaning that they were selected based on their relevance to the research questions. Phenomenological qualitative approaches aim for contextualization and illumination of a research question, and thus are not concerned with the issue of generalizability. For this reason, small sample sizes are acceptable in studies of this type, and therefore purposive sampling was appropriate for achieving the goals of the present study (Brocki \& Wearden, 2006). Attention was given to the diversity of the sample in terms of gender, age, ability, education, race, and ethnicity.

\section{Participants}

Thirteen self-identified heterosexual residents from an ALF in northern Colorado were interviewed for the purposes of the study (see Table 1 for complete demographic 
Table 1

Demographic Information of Interviewed ALF Residents

\begin{tabular}{|c|c|c|c|c|c|c|c|}
\hline Participant & $\operatorname{Sex}^{\mathrm{a}}$ & Age & Ethnicity $^{\mathrm{b}}$ & $\begin{array}{l}\text { Religious } \\
\text { Affiliation }\end{array}$ & Employment & Education & $\begin{array}{l}\text { Relationship } \\
\text { status }\end{array}$ \\
\hline 1 & $\mathrm{~F}$ & 72 & EA & None & Forest Service & Some college & Divorced \\
\hline 2 & M & 82 & AA & Methodist & Professor & Professional degree & Widowed \\
\hline 5 & M & 62 & EA & None & Radio group manager & Some college & Divorced \\
\hline 6 & $\mathrm{~F}$ & 80 & EA & Methodist & Salvation Army/Auto Parts store & $\begin{array}{l}\text { High school (10th } \\
\text { grade) }\end{array}$ & Divorced \\
\hline 7 & M & 82 & EA & Believes in God & Ceramic tile vendor/Hospice care & High school & Widowed \\
\hline 8 & $\mathrm{~F}$ & 89 & EA & Christian & Special Education teacher & Bachelor's degree & Divorced \\
\hline 9 & $\mathrm{~F}$ & 80 & EA & Protestant & Electronics factory worker & High school & Widowed \\
\hline 10 & $F$ & 78 & EA & Christian & Homemaker & $\begin{array}{l}\text { High school (11th } \\
\text { grade) }\end{array}$ & Widowed \\
\hline 11 & $\mathrm{~F}$ & 88 & EA & Methodist & Auto factory inspector & High school & Widowed \\
\hline 12 & M & 70 & EA & Mormon & Probation Department & Some college & Divorced \\
\hline 13 & $\mathrm{~F}$ & 86 & EA & Presbyterian & Homemaker & High school & Widowed \\
\hline 14 & M & 84 & EA & Baptist & $\begin{array}{c}\text { Supermarket } \\
\text { owner }\end{array}$ & High school & Divorced \\
\hline 15 & $\mathrm{~F}$ & 90 & EA & Episcopalian & Homemaker & Some college & Widowed \\
\hline
\end{tabular}

Note. ${ }^{\mathrm{a}}$ For sex, $\mathrm{M}=$ male, $\mathrm{F}=$ female.

${ }^{\mathrm{b}}$ For ethnicity, EA = European American, $\mathrm{AA}=$ Asian American. 
information). Eight women and five men participated in the study. Age of participants ranged from 62 to $90(M=80.23, S D=8.15)$. All participants were White, EuropeanAmerican with the exception of Participant 2 (P2), who identified as Asian-American. In terms of religious affiliation, participants generally identified with various Christian denominations (Methodist, Episcopalian, Mormon, Baptist, Catholic), and three participants identified as non-religious. The employment histories of participants were

diverse, and participants varied in the amount of education they had attained, from a $10^{\text {th }}$ grade high school education to a doctoral degree. All participants were currently single at the time of the interview, being either widowed or divorced.

Researchers. The primary researcher (Weston Donaldson) is a 26 year-old, European-American gay male who is a doctoral student in counseling psychology. His interest in issues surrounding older LGBT adults began after attending a training that discussed the challenges faced by that population, particularly in care settings. In addition, a research team that consists of other counseling psychology doctoral students interested in older adult research issues, as well as an experienced licensed psychologist who specializes in geropsychology, aided in the development of the project and the analysis of the data.

\section{Measures}

Semi-structured interview. Data were collected using a semi-structured interview format, with the intention of eliciting rich descriptions of participants' experience with the phenomenon of interest. The results of Asta's (2008) study served as the primary guiding theory for the present study; thus, the research questions and interview schedule were written with those in mind. Interview questions were intended 
to highlight general attitudes toward sexual minorities. Follow-up questions focusing on how participants feel they and their peers could become more comfortable with gay and lesbian fellow residents were also included. The researcher collected demographic information using a separate form for that purpose (see Appendix A). The following questions were used to explore the attitudes of heterosexual residents toward gay and lesbian peers:

- What is it like for you to talk about gay and lesbian people/homosexuality?

- Where does your reaction come from?

- What is your experience with gay and lesbian people?

- How much do your religious/spiritual beliefs play a part in your feelings about gay men and lesbians?

- What would it be like to live here with a resident who is a lesbian woman? A gay man?

- What would it be like for you if a same-sex couple (two men/women in a couple) lived in this facility?

- What would help you feel more comfortable with gays and lesbians living here in this facility?

- What might help others here become more comfortable?

\section{Procedures}

Recruitment. The researcher contacted ALFs asking to notify residents of the study, and to identify individuals who are willing to participate in 45-minute interviews on sexual orientation. Participants were recruited with the help of the facility's activities director, who was informed of the details of the study, and who then approached residents 
to ask them to participate. She was aware that only heterosexual, high-functioning residents over the age of 60 could participate, and thus helped select people appropriate for interviewing. She asked residents if they would like to talk to a student who wanted to hear their feelings on homosexuality, and explained that no matter what their views were, they would be appreciated. Further into the interviewing phase, there was a majority of neutral to favorable attitudes toward homosexuality, and at that point the researcher asked the activities director to try to directly recruit those with more negative attitudes on the topic.

Although 15 residents were originally interviewed, only 13 interviews were coded and used for the final results. One participant disclosed her identity as a lesbian during the interview, thus making her ineligible for the study due to the pre-established exclusionary criteria. Another interview was lost due to technical problems with the audio recorder. The researcher made his best attempt at remembering the main themes that came from that interview, and over the analytic process it became clear that the themes that would have come from the lost interview were present in other interviews, so no unique data appeared to be lost. Thus, only 13 of the interviews were used for the purposes of the study.

Interviews. All interviews were conducted by the primary researcher, and lasted approximately 10 to 40 minutes each. At the outset of each interview, the researcher explained his status as a graduate student in psychology, and described the general topic of the interview as well as the materials used in the interviewing process. Any questions regarding the audio recording, research topic, or other aspects of the interview were answered as genuinely and clearly as possible. Because of the nature of the topic of the 
interview, the researcher did his best to appear impartial to the topic. However, some participants inquired about his attitude toward homosexuality, and others inquired about his sexual orientation. In these cases, the researcher did his best to respond genuinely and non-defensively, and chose to disclose those aspects if asked. No participants asked about the researcher's sexual identity before or during the interview-only at the end. Thus the researcher's disclosed sexual identity did not appear to influence the participants' responses to the interview questions.

Saturation. In qualitative research, the term saturation refers to the point in data collection and analysis when there is no new information gained for a category as more data are collected (Creswell, 2007). In the data analysis process, this is realized in the integration of themes from individual cases. This means that shared themes and experiences between participants have been identified and included in master themes, with irrelevant or extraneous information excluded, and no new themes generated. Thus, for the present study, this meant that additional interviews were conducted until the analysis yielded no new information in response to the research questions (Bowen, 2008). This occurred following the interview with Participant 12, as the interviews with participants 13 through 15 yielded no unique data (although they were retained as part of the study to add to the richness of understanding).

\section{Qualitative Data Analysis}

Interviews were transcribed and then analyzed for thematic content following procedures consistent with Interpretative Phenomenological Analysis (IPA; Willig, 2001). The purpose of the analysis was to identify units of meaning in individual 
interviews, and to pull out themes that reflect the essence of the experiences described (Wertz, 2005).

Stage 1. The first stage of analysis consisted of reading and re-reading the individual transcribed interviews. Based on those readings, the researcher made wideranging and unfocused notes reflecting initial observations and thoughts of the researcher upon the first encounter with the data (Willig, 2001). This form of note taking is the most open form of data analysis.

Stage 2. In the second stage, the researcher identified themes that occurred throughout the text. Themes are intended to provide a conceptual understanding of the data, and can be presented in psychological terms (Willig, 2001). However, some themes were best kept as verbatim quotes from the participant, whereas others summarized the content of the text. The organization of data into themes was the next level of understanding the text and its essence.

Stage 3. The third stage involved grouping themes generated in stage two into broader categories of meaning. Themes from individual texts were listed, and then grouped according to they ways they relate to one another, be it through meaning, reference, or a hierarchical relationship (Willig, 2001). This stage was the first attempt at structuring the data in order to capture the essence of the phenomenon under study.

Stage 4. The fourth stage consisted of producing a summary table of the theme clusters, including direct quotes from the text itself (i.e., the participant's own words). At that point, themes from stage two that did not relate to the research questions were excluded, and themes that did not fit well in a specific category were not retained, depending on the interest and intent of the researcher (Willig, 2001). 
Integration of cases. When integrating several cases, themes from individual cases were grouped into master themes that were intended to represent the essence of the shared experience of participants relating to the phenomenon of interest. The results of integration were mapped out in a summary table, listing theme clusters as parts of the master themes. During the integration of theme clusters into master themes across cases, it became necessary to refer to the original text of the interviews, which resulted in some theme clusters being subsumed by others, thus resulting in more distinct master themes. Only one theme cluster was omitted due to being irrelevant to the topic of the present study.

\section{Trustworthiness}

Within qualitative research, trustworthiness is the means by which the validity of the research results and conclusions is assured. Several approaches addressing trustworthiness were employed in order to ensure the quality and rigor of the study. Creswell (2007) recommends using at least two strategies to confidently and adequately address the issue of trustworthiness. In the present study, the following four strategies were included in the methodology.

Clarifying research bias. Consistent with many phenomenological studies, the researcher bracketed his personal experiences and biases in order to be clear about his intention in the study and the assumptions he might bring into it. The researcher's paradigms, beliefs, and intent have been made clear from the inception of the study, and were made explicit throughout the course of the research project.

Research journal and reflexivity. Additionally, the primary researcher engaged in self-reflection by keeping a research journal that included hypotheses, questions, 
concerns, additions, philosophical musings, methodological considerations, and other topics related to the process of conducting the research. Such reflexivity is intended to make the researcher's role as the interpreter of data more explicit and remain aware of assumptions and biases that could influence the research process (Creswell, 2007; Morrow, 2005). In this study, the journal provided a way for the primary researcher to document his experience with each participant, to explore his conclusions and questions that emerged from data analysis, and to maintain self-awareness about his interpretation of the data.

Peer consultation. Consulting with peers on a research team during data analysis can aid in verifying conclusions, generating alternative interpretations, and monitoring researcher bias (Creswell, 2007; Morrow, 2005). During the processes of data collection and data analysis, the primary researcher consulted with a research team consisting of peers and a counseling psychology faculty member trained in qualitative methodology. Research team members provided feedback on themes and subthemes generated by the analysis process, shared alternative views on what the data showed, and confirmed the final conclusions that were drawn by the primary researcher.

Thick description. Thick description enhances the reliability and transferability of the research results, as it allows readers to make their own interpretations and connections with other research domains and populations (Creswell, 2007). The written transcripts of the audio-recorded interviews in this study provided a thick description of the participants' words, including any pauses or non-verbal communication that occurred during the interviews. This approach added increased detail to understanding 
participants' responses, particularly as emotional indicators such as sighs, laughter, and sadness were included in the transcript text. 


\section{Results}

\section{Master Themes and Subthemes}

The analysis resulted in eight master themes representing the attitudes of the heterosexual ALF residents who were interviewed (see Table 2). The themes include the feelings, reactions, experiences, and explanations that the participants provided. The first research question guiding the present study focused on how heterosexual ALF residents react to the idea of gay and lesbian people living in their facilities, and themes 1 through 3 appear to relate to that question. Themes 4 through 8 appear to answer the second research question, as to how previously identified factors play a role in their reactions to gay and lesbian ALF residents.

Theme 1: Presence of gay and lesbian residents in ALFs. When asked about the possibility of having gay and lesbian residents in their facility, participants expressed a range of feelings about the existence of gay and lesbian residents, from doubt that there would be such residents in their facility, to feeling that there probably are gay and lesbian residents living among them. To that effect, one woman said, "I got a feeling that there are some...but I don't know... (chuckled) and I'm not going to try to find out" (P11). Other participants who suspected that gay and lesbian people lived among them said that they would probably not find out about them. One woman said that those she suspected were "kind of quiet, and that's good" (P12). Still others believed that gay and lesbian people would not be allowed in the facility, as one resident said, "In the first place, I 
Table 2

Themes and Subthemes for Heterosexual ALF Residents' Attitudes Toward Gay/Lesbian Peers

1. Presence of Gay/Lesbian Residents in ALFs

a. Gay and lesbian residents are unlikely to live in an ALF.

b. ALF residents are unaware of the sexual orientation of their peers.

2. Reactions to Gay/Lesbian ALF Residents

a. Heterosexual ALF residents are accepting and non-accepting of gay and lesbian residents.

b. Gay and lesbian residents should respect boundaries of privacy.

c. Pushing one's sexuality on others is wrong.

d. Many heterosexual ALF residents are comfortable coexisting with differences.

3. Peer Attitudes Toward Gay/Lesbian Residents

a. Other ALF residents are probably homophobic.

b. ALF residents interact with one another infrequently.

c. Homosexuality is an uncommon topic in the lives of ALF residents.

4. General Attitude Toward Homosexuality

a. Most residents are comfortable talking about homosexuality.

b. Residents hold both favorable and unfavorable views of homosexuality.

c. ALF residents described their common humanity with gay and lesbian people.

d. Residents' favorable and unfavorable attitudes were stable over time.

5. Experience of ALF Residents with Gay/Lesbian People

a. Most ALF residents had some experience with gay men and lesbians.

b. Experiences with gay men and lesbians varied from positive to negative, personal to impersonal.

6. Factors in Residents' Attitude Formation and Change

a. Homosexuality is more accepted in today's society.

b. Attitudes toward homosexuality become more accepting with age.

c. Residents' global moral beliefs and values influence their attitude toward gay men and lesbians.

7. Residents' Knowledge of Homosexuality

a. ALF residents claim little knowledge of homosexuality.

b. ALF residents tend to believe homosexuality is not a choice.

8. Religion and Homosexuality

a. Religious beliefs influence residents' feelings about homosexuality.

Note. All participants $(n=13)$ were represented in themes $2,3,4$, and 5. A majority $(n>$ 9) of participants was represented in themes 1, 6, 7, and 8. 
don't think they'd let 'em in. I'm afraid they wouldn't. I think they would ask us first....I really feel like that they wouldn't—-That wouldn't live here." (P13).

It appeared that another aspect of thinking about gay and lesbian residents in their facility was the fact of considering the sexual orientation of other residents. On this point, participants tended to say that they either did not want to know others' sexual orientation, or that it would simply never come up because they would not ask about it directly. For example, one resident said, "We got some odd people, but we don't say, 'Are you gay?' They wouldn't know what I was talking about” (P15). Another man said, "The sexualities or orientations of my neighbors has never been a factor, has never been important for me to either want to know" (P2).

Theme 2: Reactions to gay and lesbian ALF residents. The residents interviewed also shared the ways they might react toward gay and lesbian residents. In the case that they had actually known a gay or lesbian ALF resident, they shared how they did react. A first way to understand their reactions seemed to be in the terms of acceptance and non-acceptance of sexual minority residents. The first participant's response was quite positive:

"I think I'd be enriched. Um we have a lady here that was raised in an orphanage, and ever time I talk to her I'm more enriched and empowered. I'm sure if I was living with a lesbian then she would do the same thing. I think I would be better for her friendship. More well rounded, well you know what I mean.” (P1) Some residents stated that they would not treat gay and lesbians differently than heterosexual peers, saying that they are "just two more human beings" (P2). On the other hand, other residents indicated that they would be reticent to engage a fellow resident 
they knew was lesbian or gay. One woman said, "I would be shocked, you know...to think I knew somebody here that was. I wouldn't say hello. You know, I wouldn't be mean to [a lesbian resident]." (P10). Another man spoke of having little choice in encountering gay and lesbian people because of the nature of the facility, and said, "we just have to tolerate it" (P12)." At times, residents were not sure why they would have the reaction they thought, as one woman stated:

“It's okay with me. I just would stay away. That's all. I mean, I wouldn't associate with 'em....I don't know if I would be friendly with 'em. I don't think I would, and don't ask me why because I'm not sure" (P11).

Many times, participants stated that they were not bothered by the presence of gay and lesbian residents, as long as they were not roommates with them.

"I don't know if I would want to room with one or not. I think I would, but I would like to talk to them first and find out... uh... I would, you know, talk to them and get acquainted with 'em." (P13)

Participants also highlighted the need for boundaries and privacy, saying that they felt comfortable with the idea of gay and lesbian residents as long as there were appropriate boundaries and the necessary privacy around romantic and sexual behavior. "You know, the way I look at it, what they do in their own privacy—Should remain that way. You know, I mean, now, if a male or female, you know, uh, gay or lesbian, performed a - gave somebody a blowjob out in the hall, then yeah. I mean, as long as they keep it, you know, privacy." (P7) 
A related idea that many residents shared was the feeling that gay and lesbians should not push their sexuality on others. These reactions involved images of sexual minorities shoving their sexuality on others, or "throwing it in their face" (10).

Finally, participants described their ability to coexist with difference. This attitude could be described by the phrase "live and let live," which some participants used directly. Residents with these sentiments did not feel that they would be affected in any way by living with gay and lesbian people, and they believed that "everybody has their own way of doing things" (P6).

Theme 3: Peer attitudes toward gay/lesbian residents. When asked how they felt other residents in their facility would feel and react toward gay and lesbian residents, the majority said that other residents would have negative feelings and reactions.

"Well this is not a high-end wealthy facility, so the people in here are simple.

They have an education that doesn't stretch their mind too much, and so they're apt to be less liberal. They're apt to be more uptight and uncomfortable. So I don't know if you'll run into more people like I'm talking...or if you're gonna find yourself in a fight (laughed).” (P1)

Interviewed residents felt that their peers would not be accepting, and even be "horrified" (P5) at the idea of living with gay and lesbian people. Many also expressed anger as a result of others' negative feelings, calling it a "lack of compassion" (P2).

“Uh, some would probably accept it. Uh, there's numbers that wouldn't. You know, especially you're old group. Old, old people like me.” (P7)

One woman reported that she had previously known a lesbian woman in the facility, and described others' reactions and how they impacted her: 
"She wasn't easy to get close to. She was very deaf, and, uh-I couldn't get close to her. Nobody did. Now, this was something I was amazed at. People warned me about her. And that was a shock to me, and, uh, I said, 'Why? Why? What, uh...' Just because she was gay, lesbian.” (P8)

Many residents interviewed said that they could only guess at how other residents would actually feel and react because they did not interact very much with their peers. Several residents interviewed said that they keep to themselves, and that when they do socialize with other residents, they do not talk about sexuality or sexual orientation. One woman said, "We never talk about things like that, and we sit around, and we eat dinner together" (P15).

Moreover, the majority of participants reported that homosexuality is an uncommon topic in their lives. Some said that there are "more important things to think and talk about" (P8). Others said the topic was never "brought up" (P2). Even when participants suspected that someone they knew was gay or lesbian, they often said that they would never broach the topic with that person or with other residents.

Theme 4: General attitude toward homosexuality. All participants but one (P10) reported that they were comfortable talking about the topic of homosexuality, regardless of their beliefs or attitude about it. Most often, they said that they were "not bothered" by the topic of the interview. In that sentiment, one man said, "It would be the same as you would talking about, talking about the weather or about football or about movies or whatever." (P2)

Participants described their general feelings about the topic of homosexuality, and expressed a range of opinions. Some participants felt that homosexuality was "natural" 
and "normal," whereas other participants stated that homosexuality was bad for society, that it is unimportant, or that they did not "approve of" or "like" it. One resident said, "There are more important things to think about and talk about" (P8). Another man said, "It's, uh, so well covered now that we're going to go to Hell in a handbasket (sighed)" (P12).

Many participants shared positive feelings toward gay and lesbian people, saying that they are "nice people" (P9), and that they felt sorry for them because of the prejudice they encounter. One woman was able to acknowledge that gay men and lesbians are not all the same, and that some might receive different reactions than others:

"I can't say that every one of 'em is A-OK 'cause there's a few that get pretty rough, you know? There's a few that out of the bunch that needs to be kind of took down a little bit.” (P6)

Participants also expressed a belief of common humanity, emphasizing that gay and lesbian people are fellow human beings, who therefore deserve respect. They also indicated that they saw no difference between heterosexual people and gay and lesbian individuals. As one woman said, "We're all alive together as a family" (P8).

Several residents indicated that their attitude had been stable over their lifetime, saying that they had always felt the same way about gay and lesbian people, and planned to always have the same feelings. They believed nothing would influence their opinion, being "set in [their] ways" (P12).

Theme 5: Experience of ALF residents with gay/lesbian people. All residents who were interviewed had some experience with or exposure to gay and lesbian people during their lifetime. However, participants described a range of experience in terms of 
both the amount and quality of experiences with gay and lesbian individuals. Many participants described positive experiences they had had with gay and lesbian individuals, including friends, co-workers, family members, and even staff at the ALF. Speaking of a gay man who worked with her husband, one participant said, "I loved him...[he was] an exceptional human being" (P1). Another participant said he roomed with a gay man in college, and the experience ended up being more positive than he had imagined: "He was a hoot. And he and I got along great....He turned out to be a really, really nice guy." (P5) Several participants had gay family members, whether siblings, children, or other relatives. It seemed that these relationships were generally positive, even when the resident's overall view of homosexuality was less positive.

"My own daughter came to both me and my wife, her mommy, when she was in high school....She didn't write us a letter, she just said, "Well, you should know that I'm this way." See? And, we said, "Well, we love you just the same." You know? We don't, we didn't hesitate one moment to even discuss it. We just said, “Okay, so you're this way. We still love you."...And she is, she now has a, uh, a wife. I'm really proud of both of them, you know? I'm both proud of my daughter and my daughter-in-law, you know? (P2)

Another man shared about his son:

"My son was gay. Uh, I went to most gay functions to support him. And I went to all the coordination, and, uh, I support him all the way. I even bowled on a gay league. Uh, our bowling name was Four Queens and a Straight. (Laughed.) And, anyway, and all the, all the young men came and said, (coughs) "I wish my dad could be like you and accept me.” (P7) 
Although one woman said she had a difficult time understanding her gay brother, she still felt a family bond with him:

"I keep telling everybody he's my brother. I mean, it's his choice, his way of life, and I can't change him. I wouldn't even try ‘cause I wouldn't know how to go about doing it, anything like that." (P11)

Some participants shared negative experiences they had had with gay or lesbian people. Several participants had both positive and negative experiences, or experiences that were uncomfortable at first but that became more positive over time. One woman described feeling harassed by a nurse who she believed was a lesbian. Another resident shared an experience where her gay brother and his partner came to live with her for some time. She said, "He come to live with me, and, um, he brought his mate with him....I guess he felt as uncomfortable around me as I did around him" (P11).

One final aspect of participants' experience with gay and lesbian people was their early experiences with homosexuality. One woman described an experience in her youth where she felt a female friend was flirting with her. Another woman believed that she might have known some "queer" people in high school. Participant 2 , in particular, shared several experiences from his early life where men propositioned him for sex. He had this to say about the experiences:

"Well, uh, I, uh, well, obviously not being that way oriented, I repulsed 'em both times, just like that without, you know, and I guess maybe I can say I'm fortunate or maybe I did the right thing at the right time and they, they didn't pursue their proposal. They just made an attempt and I rejected them and they went away." (P2). 
Other participants had limited or no experience with gay and lesbian people. One man indicated that he intentionally avoids gay and lesbian people, thus resulting in limited experience with them:

"I try not to know anybody at all, but you blunder, you blunder-in day-to-day life you run across somebody who's gay....I've been pretty separate from a lot of things; that's one of 'em....I just don't, uh, choose to, uh, associate with those people.” (P12)

Other participants mentioned that they had been exposed to gay and lesbian individuals through the media, even when they did not have any personal experiences. Often, their first exposure to homosexuality was through media such as news, books, or television. One man reported watching a lesbian tennis player on television. Another participant stated that she had read about some gay and lesbian people, and that she had seen homosexuality in movies, which "shocked" her (P10). Another man was upset about being exposed to homosexuality in the media, saying that "there's too much of it on the news" (P12).

Theme 6: Factors in residents' attitude formation and change. Participants shared several factors that they believed were significant in forming their initial attitudes about gay and lesbian people. They also identified factors that served in changing their perceptions and beliefs about homosexuality. Participants reported that one of the most common reasons for their shifting attitudes toward gay and lesbian people was the general increase in acceptance of homosexuality in society.

"The whole attitude of society has changed during those years. Um...people got more educated, they got more exposed, and they become comfortable with 
something that is not a horrible thing. It's a very natural thing and it's a very...um...obviously ok thing. So I just went along with society.” (P1)

Other participants pointed to age as a factor in being both more and less accepting of gay and lesbian people.

"I've lived many years, and, by now, you're comfortable with most everything....I'm just happy to be, uh, waking up each morning and meeting whoever it is to meet and what they are with me'"' (P8)

Another resident described the ways her attitudes have changed over the years:

"I'm 72, so when I was a teenager that's quite a while ago. And this topic has developed through the years from the time I was a teenager. Back then homosexuals had naughty connotations. They were looked down on, they were feared, they were not wanted, and that's how I started out. So I had to grow and develop from that point to where I am now. So it's a little foggy for me because the kids today have no problem with their-they can answer questions about homosexuals, they can think about 'em, they can be in their company completely relaxed. That's not the case for a person that is $72 . "(\mathrm{P} 1)$

Participants also identified global moral beliefs or value orientations that contributed to the way they viewed other people, including gay and lesbian people. These beliefs included valuing equality of all people, positive views of others, and antiprejudice feelings. Some spoke of the relative importance of sexual orientation when considered with other aspects of people. One resident said, "There are so many more important things in relationships with people and life." (P8). Another resident exhibited a relativistic point of view, when she said, "Everybody's got their own way of thinking and 
living. You live your life the way you want to live it, not the way I or anybody else thinks that you should" (P11)

Theme 7: Residents' knowledge of homosexuality. Participants expressed the amount of knowledge regarding homosexuality that they had or didn't have. Several participants claimed no knowledge or understanding of homosexuality and the lives of gay and lesbian people. However, many participants expressed some ideas on the apparent cause of homosexuality. These opinions clustered around the beliefs that homosexuality is a choice, or that homosexuality is an innate characteristic. Among the participants interviewed, a greater number sided with the "born that way" belief.

"Some people are born with a leaning towards homosexuality. I believe that. I think we are born and given by God and their birth a tendency to be homosexuals." (P1)

One man, who had a gay son, said he consulted a mental health professional on the matter:

"You know, and, we went to my wife, who says, we go to a psychiatrist, and he said, "They're born that way." I says, or he said there are religions who say they could cure him. He says, "You don't care." He says, "They're born that way." (P7)

Other residents compared being gay or lesbian to having a health condition or a congenital disability:

"Regardless, I mean, you might have TB or something, or you might have another serious disease, but homosexuality is made up of people that you were born with 
and you couldn't help that. I mean, there's something that goes wrong. You get a little more female, don't you? I don't know for sure.” (P13).

Many participants also reported that they believed homosexuality is a choice.

Some hypothesized that people are converted to homosexuality, while others believed that it was simply a preference on the part of those individuals.

"I think that's choice more than anything. It isn't something forced on. I think they just have made up their mind. That's, uh, how they want to be, and that's it. And if, uh—very seldom can you change 'em if they make up their mind to that. You're not going to change 'em." (P6)

Theme 8: Religion and homosexuality. Participants were asked directly what role their religious or spiritual beliefs played in their feelings toward gay and lesbian people. This elicited a range of answers, from favorable to unfavorable religious attitudes. Some said their beliefs would "embrace homosexuality" (P13), and others said that gay and lesbian people would "burn in Hell" (P12). Others held to what they had read in the Bible or heard in their services regarding homosexuality. One woman said, "It says in the Bible that it's a sin, but they can be forgiven" (P9). However, that same woman said that because she is a Christian, she loves everybody and does not hate or judge others.

One resident's religious beliefs on homosexuality were also connected to her beliefs about the purpose of sex and procreation:

“Well, I think God made us men and women, but I don't think you should-I think that you're supposed to pair up a man and a woman. I don't think that two people of the same sexes should be involved with each other. I, I can't 
understand because that's for-it's made for reproductive - have children, er, and, um, (laughs) when it's the same sexes, there's going to be no children." (P11) One man described how his reaction to homosexuality differs even from that of his church:

"Well, I get religious beliefs, and I follow the doctrine of the church, and I just don't—I'm just one of those people who just won't... sway from it at all. Our church is always sending stuff out, um, occasionally, about, uh-from Salt Lake, and, uh, about homosexuality, and course they've changed a little bit in the fact that they, they're saying you got to put up with it, (sighs) but I just ignore it." (P12)

Some participants also expressed feelings that religion was irrelevant to homosexuality and how they perceive gay and lesbian people. They had a difficult time describing how religion played into their feelings at all, saying that they "haven't really thought about it" (P5). Finally, some participants commented on the homophobia they perceived in religious institutions. One woman recounted the experience of her Catholic uncle who had a lesbian daughter, and described the pain he felt because the church did not accept her for who she was. This elicited a strong emotional response from the participant, as she said:

"I wanna cry just thinking about it. How many people in the Catholic church feel they can't go there because somebody is a homosexual. Good God....I think religion and spirituality should mind their own business and stay out of topics that have nothing to do with them.” (P1) 


\section{Discussion}

The present study sought to explore and understand the ways that heterosexual ALF residents react to the idea of gay and lesbian people living in their facilities, and how factors that have been identified in previous research play a role in the way they might relate to gay and lesbian residents. Overall, a range of opinions on the topic of homosexuality emerged from the interviews in this study. The results seem to indicate that the attitudes gay and lesbian residents would encounter in assisted living facilities would include everything from non-acceptance, to indifference, to acceptance. Factors such as experience with lesbians and gay men, religious beliefs, age, societal views, and personal values appeared to be important in the formation of their attitudes.

The findings appear to reflect a general trend that gay and lesbian residents are still very much "the other" in an ALF setting, and sexual orientation did not seem to be a salient concept among the residents who were interviewed. Heterosexual residents seem to believe that gay and lesbian residents would either not be admitted to the facility, or would not disclose their sexual orientation if they were to be allowed in. Residents tended to believe that the topic of homosexuality would not come up in conversation, which many seemed to think was desirable. Finally, no matter their own attitude toward sexual minorities, residents tended to believe that other residents in the facility would be homophobic, and that it would be difficult for gay men and lesbians to live in their facility. These results appear to demonstrate the presence of homophobia and heteronormativity among residents in ALF settings. 
The interviews revealed some ways that residents would interact with gay and lesbian peers in the facility. The majority of participants said that they would not be "bothered" by having gay and lesbian people in their facility, but were very clear about defining appropriate behavior and describing boundaries that would help them feel safer. This may reflect a heterosexist bias that would not exist if those residents were talking about a heterosexual resident or opposite-sex couple. Even within some interviews, participants seemed to vacillate between an accepting stance and fears about interacting with gay and lesbian residents. At times, it was difficult to understand how residents would actually behave due to their ambivalent responses.

The finding that some residents would avoid or restrict interaction with gay and lesbian people in their facility underscores the importance of this study, since research on social isolation points to negative physical and mental health outcomes when people in care settings are isolated from their peers (Cacioppo, Hughes, Waite, Hawkley, \& Trusted, 2006; Cornwell \& Waite, 2009; Thompson \& Heller, 1990). It is also concerning that residents said they would not view or treat gay and lesbian residents differently, because such attitudes might mean that they would not make an effort to reach out toward sexual minority residents. The majority of participants said they do not interact much with even their heterosexual peers, thus the level of social engagement might be just as low or lower for gay and lesbian residents.

In looking at how specific demographic and personal variables may have influenced participants' responses, some potential trends seemed to emerge. Most notably, residents' religiosity appeared to have a strong influence on the way they thought about homosexuality, with a majority of religious participants describing 
ambivalent or unfavorable attitudes toward gay men and lesbians. Attitudes did not seem to vary with participants' age, but regardless of age, participants tended to think that their older peers would have more negative attitudes. The majority of male residents in the study described favorable attitudes toward sexual minorities, whereas female residents equally described favorable, unfavorable, and ambivalent attitudes. This finding is contrary to research on attitudes toward homosexuality that shows men having more unfavorable attitudes than women, and therefore may be a result of sampling bias. (Herek, 1988). There were no noticeable trends in participants' attitudes based on education or employment.

Another significant aspect of this study was the way that participants seemed to experience the interview process. Many residents indicated how they were being affected by talking about the topic of homosexuality. Despite saying they were comfortable talking about homosexuality, some residents said that they were becoming nervous during the interview. Others became angry because of the injustices they saw toward sexual minorities, and some said that they were going to continue to reflect on this topic and explore it through personal writing. A few participants became tearful when describing tender personal experiences. Finally, a few residents appeared concerned that their responses were in some way inadequate, and apologized throughout the interview, minimizing their knowledge and experiences. This range of affective responses to the interview process appeared to mirror the range of attitudes found among the residents who were interviewed. 


\section{Limitations}

The present study was subject to several limitations, which may impact the transferability of the results to all ALF residents. First, the diversity of the sample was limited to that of a small city in northern Colorado, in which the majority of residents are White, non-Hispanic. Although aspects such as gender, race, ethnicity, education, and age were considered during sampling and data analysis, other variables were uncovered that should be explored further, such as the amount of time residents had lived in the facility, their cognitive ability, and factors related to the facility itself. However, the participants appeared to be typical of the facility they lived in, and of the community in which the facility is situated. For that reason, the sample may represent the people that gay and lesbian residents in the area would encounter in such a facility.

Although purposive sampling was used, the sample was still a volunteer sample, thus residents who were willing to be interviewed may be different in some ways from those who refused to be interviewed. Although some participants displayed unfavorable attitudes, it seemed that many residents who were approached for participation in the study refused because of the nature of the topic. This may have led to a bias among the sample of residents interviewed, whereby they were more comfortable with the topic and generally more accepting of gay and lesbian people. 


\section{Future Directions}

Because of the age of the residents interviewed, the results should be interpreted within the generational and cohort contexts of those individuals, as well as within the context of the current state of opinion toward homosexuality in the United States. Over the past four decades, opinions on the morality of homosexuality have become more favorable toward sexual minorities, and willingness to restrict the civil liberties of gay and lesbian people has decreased. For the first time, in the summer of 2011, several national surveys showed that more than half of people living in the United States favor same-sex marriage, indicating a significant shift in general attitudes toward sexual minorities (PPRI, 2011). At this time, there is still a significant gap between the attitudes of adults age 65 and older and those in the so-called "Millennial Generation" (age 18-29) on public policies favoring gay and lesbian people (PPRI, 2011). Based on these results, it appears that older adults tend to have less favorable attitudes toward homosexuality than younger generations, but that attitudes have generally become more favorable over time, across generations. The attitudes of the older adults in this study seem to represent both of these trends, leading to more questions than answers.

It is clear that more research should be done to further explore the meaning of these results, and to continue to promote affirmative attitudes and practices toward sexual minorities in aged care facilities. As this study explored a somewhat novel question, it appeared reasonable to maintain the narrower and more approachable focus on gay men and lesbians. However, future studies should explore attitudes of heterosexual older 
adults toward bisexual, transgender, and other queer-identified older adults using similar methods, and with equal rigor. This is particularly relevant for transgender older adults, who not only face transphobic attitudes but also have transgender-specific health concerns that should be carefully and respectfully addressed in such facilities (Blevins, 2006; Cook-Daniels, 2007).

Residents interviewed in this study were unable to identify ways that they or their peers could become more accepting of gay men and lesbian women in their facilities. However, existing research has shown positive health effects from social engagement between residents at LTC and ALF residences, with enjoyment of mealtimes and perceived friendliness of fellow residents and staff being a significant predictor of life satisfaction for ALF residents (Park, 2009). In addition, a cohesive, supportive facility environment is associated with greater facility satisfaction and lower depression scores for residents (Mitchell and Kemp, 2000). Further research should explore interventions, policies, and other factors that could create these conditions among all residents in care facilities in order to develop a healthier environment for sexual minority residents.

Finally, researchers should explore the above research questions in other care settings for older adults, such as LTC facilities, hospitals, and hospice organizations. In addition, not only residents and patients should be interviewed, but also staff and administrators in those institutions, because they constitute a major part of residents' experiences within a facility.

\section{Conclusions}

The findings of the present study describe a range of reactions and attitudes of heterosexual ALF residents toward their gay and lesbian peers. Regardless of their 
attitudes, residents seemed mostly unaware of sexual minorities living among them, and felt that gay men and lesbians would be unwelcome in their facility. These findings become even more significant knowing that there were actually LGB residents living in that ALF during the time of the interviews. It is hoped that by using information from this and similar research explorations, conditions for all sexual minority older adults in post-retirement care settings can be improved. 


\section{References}

Abbott, D. \& Howarth, J. (2007). Still off limits? Staff views on supporting gay, lesbian, and bisexual people with intellectual disabilities to develop sexual and intimate relationships? Journal of Applied Research in Intellectual Disabilities, 20, 116126.

Addis, S., Davies, M., Greene, G., MacBride-Stewart, S., \& Shepherd, M. (2009). The health, social care and housing needs of lesbian, gay, bisexual and transgender older people: A review of the literature. Health and Social Care in the Community, $17,647-658$.

Administration on Aging (2000). Profile of Older Americans, 2000. Washington DC: National Institute of Mental Health.

Albarracin, D., Zanna, M. P., Johnson, B. T., Kumkale, G. T. (2005). Attitudes: Introduction and scope. In D. Albarracin, B. T. Johnson, \& M. P. Zanna, (Eds). The Handbook of Attitudes, (pp. 3-19). New York: Psychology Press.

Asta, E. L. (2008). Older adults' attitudes toward gay and lesbian peers in long term care and assisted living facilities. Unpublished thesis.

Blevins, D. (2006). End-of-life issues for LGBT older adults. Lesbian, Gay, Bisexual, and Transgender Aging: Research and Clinical Perspectives, pp. 206-226. New York: Columbia Press.

Bowen, G. A. (2008). Naturalistic inquiry and the saturation concept: A research note. Qualitative Research, 8, 137-152. 
Brocki, J. M., \& Wearden, A. J. (2006). A critical evaluation of the use of interpretative phenomenological analysis (IPA) in health psychology. Psychology and Health, 21, $87-108$.

Brotman, S., Ryan, B., \& Cormier, R. (2003). The health and social service needs of gay and lesbian elders and their families in Canada. The Gerontologist, 43, 192-202.

Butler S. (2004) Gay, lesbian, bisexual and transgender (GLBT) elders: the challenges of this marginalized group. Journal of Human Behaviour in the Social Environment, $94,25-44$.

Cacioppo, J. T., Hughes, M. E., Waite, L. J., Hawkley, L. C., \& Trusted, R. A. (2006). Loneliness as a specific risk factor for depressive symptoms: Cross-sectional and longitudinal analyses. Psychology and Aging, 21, 140-15.

Cahill, S., South, K., \& Spade, J. (2000). Outing age: Public policy issues affecting gay, lesbian, bisexual, and transgendered elders. New York : The Policy Institute of the National Gay and Lesbian Task Force Foundation.

Cook-Daniels, L. (2007). Trans elder health issues. Retrieved from http://www.forgeforward.org/handouts/.

Cook-Daniels, L. (1997). Lesbian, gay male, bisexual and transgendered elders: Elder abuse and neglect issues. Journal of Elder Abuse and Neglect, 9, 35-49.

Cornwell, E. Y., \& Waite, L. J. (2009). Social disconnectedness, perceived isolation, and health among older adults. Journal of Health and Social Behavior, 50, 31-48.

Creswell, J. W. (2007). Qualitative Inquiry and Research Design: Choosing Among Five Approaches. ( $2^{\text {nd }}$ Ed.) Thousand Oaks, CA: Sage Publications, Inc. 
D’Augelli, A. R., \& Grossman, A. H. (2001). Disclosures of sexual orientation, victimization, and mental health among lesbian, gay, and bisexual older adults. Journal of Interpersonal Violence, 16, 1008-1027.

Dean, L., Meyer, I. H., Robinson, K., Sell, R. L., Sember, R., Silenzio,... \& Xavier, J. (2000). Lesbian, Gay, Bisexual, and Transgender Health: Finding and Concerns. Journal of the Gay \& Lesbian Medical Association, 4, 102-151.

Eagly, A. H., \& Chaiken, S. (1993). The psychology of attitudes. Orlando, FL: Harcourt Brace Javonovich.

Elia, J. P. (2003). Queering relationships: Toward a paradigmatic shift. Journal of Homosexuality, 45, 61-86.

Grant, J. M. et al. (2010). Outing age 2010: Public policy issues affecting gay, lesbian, bisexual, and transgender elders. New York: The Policy Institute of the National Gay and Lesbian Task Force Foundation.

Hash, K., \& Cramer, E. (2003). Empowering gay and lesbian caregivers and uncovering their unique experiences through the use of qualitative methods. Journal of Gay \& Lesbian Social Services, 15, 47-63.

Hamburger, L. J. (1997). The wisdom of non-heterosexually based senior housing and related services. Journal of Gay and Lesbian Social Services, 6, 11-25.

Herek, G. M. (2007). Confronting sexual stigma and prejudice: Theory and practice. Journal of Social Issues, 63, 905-925.

Herek, G. M. (1988). Heterosexuals' attitudes toward lesbians and gay men: Correlates and gender differences. Journal of Sex Research, 25, 451-477. 
Hinrichs, K. L. M., \& Vacha-Haase, T. (2010). Staff perceptions of same-gender sexual contacts in long-term care facilities. Journal of Homosexuality, 57, 776-789.

Hughes, M. (2007). Older lesbians and gays accessing health and aged-care services. Australian Social Work, 60, 197-209.

Jackson, N. C., Johnson, M. J., \& Roberts, R. (2008). The potential impact of discrimination fears of older gays, lesbians, bisexuals, and transgender individuals living in small- to moderate-sized cities on long-term health care. Journal of Homosexuality, 54, 325-339.

Jackson, S. (2006). Interchanges: Gender, sexuality, and heterosexuality: The complexity (and limits) of heteronormativity. Feminist Theory, 7, 105-121.

Johnson, M. J., Jackson, N. C., Arnette, J. K., \& Koffman, S. D. (2005). Gay and lesbian perceptions of discrimination in retirement care facilities. Journal of Homosexuality, 49, 83-102.

Korfhage, B. A. (2006). Psychology graduate students' attitudes toward lesbians and gay men. Journal of Homosexuality, 51, 145-159.

LGBT Movement Advancement Project (MAP), \& Services and Advocacy for Gay, Lesbian, Bisexual, and Transgender Elders (SAGE). (2010). Improving the Lives of Older LGBT Adults.

Loftus, J. (2001). America's liberalization of attitudes toward homosexuality: 1973 to 1998. American Sociological Review, 66, 762-782.

McLeod, A. C., Crawford, I. \& Zechmeister, J. (1999). Heterosexual undergraduates' attitudes toward gay fathers and their children. Journal of Psychology and Human Sexuality, 11, 43-62. 
Mitchell, J. M. \& Kemp, B. J. (2000). Quality of life in assisted living homes: A multidimensional analysis. Journal of Gerontology: Psychological Sciences, 55B, P117-P127.

Mohipp, C. \& Morry, M. M. (2004). The relationship of symbolic beliefs and prior contact to heterosexuals' attitudes toward gay men and lesbian women. Canadian Journal of Behavioural Science, 36, 36-44.

Morrow, S. L. (2007). Qualitative research in counseling psychology: Conceptual foundations. The Counseling Psychologist, 35, 209-235.

Morrow, S. L. (2005). Quality and trustworthiness in qualitative research in counseling psychology. Journal of Counseling Psychology, 52, 250-260.

National Senior Citizens Law Center (NSCLC) (2011). LGBT Older Adults in Long-Term Care Facilities: Stories from the Field. Retrieved May 16, 2011 from lgbtlongtermcare.org.

Newman, B. C., Dannenfelser, P. L., \& Benishek, L. (2002). Assessing beginning social work and counseling students' acceptance of lesbians and gay men. Journal of Social Work Education, 38, 273-288.

Park, N. S. (2009). The relationship of social engagement to psychological well-being of older adults in assisted living facilities. Journal of Applied Gerontology, 28, 461481.

Public Religion Research Institute (PPRI). (2011). Generations at odds: The millennial generation and the future of gay and lesbian rights. Washington, DC: Public Religion Research Institute.

Quam, J. K. \& Whitford, G. S. (1992). Adaptation and age-related expectations of older 
gay and lesbian adults. The Gerontologist, 32, 367-374.

Shankle, M. D., Maxwell, C. A., Katzman, E. S., \& Landers, S. (2003). An invisible population: Older lesbian, gay, bisexual and transgender individuals. Clinical Research and Regulatory Affairs, 20, 159-182.

Smith, L. A., McCaslin, R., Chang, J., Martinez, P., \& McGrew, P. (2010). Assessing the needs of older gay, lesbian, bisexual, and transgender people: A service-learning and agency partnership approach. Journal of Gerontological Social Work, 53, 387401.

Stein, G. L., Beckerman, N. L., \& Sherman, P. A. (2010). Lesbian and gay elders and long-term care: Identifying the unique psychosocial perspectives and challenges. Journal of Gerontological Social Work, 5, 421-435.

Stein, G. L. \& Bonuck, K. A. (2001). Physician-patient relationships among the lesbian and gay community. Journal of the Gay and Lesbian Medical Association, 5, 87-93.

Thompson, M. G. \& Heller, K. (1990). Factors of support related to well-being:

Quantitative social isolation and perceived family support in a sample of elderly women. Psychology and Aging, 5, 535-544.

Tolley, C. \& Ranzijn, R. (2006). Predictors of Heteronormativity in residential aged care facilities. Australasian Journal on Ageing, 25, 209-214.

Warner, M. (1991). Introduction: Fear of a queer planet. Social Text, 9, 3-17.

Wertz, F. J. (2005). Phenomenological research methods for counseling psychology. Journal of Counseling Psychology, 52, 167-177.

Whitley, B. E. (2002). Gender-role variables and attitudes toward homosexuality. Sex Roles, 45, 691-721. 
Wilkinson, W. W. (2006). Exploring heterosexual women's anti-lesbian attitudes. Journal of Homosexuality, 51, 139-155.

Willig, C. (2001). Introducing qualitative research in psychology: Adventures in theory and method. Maidenhead, GB: Open University Press.

Wright, S. L., \& Canetto, S. S. (2009). Stereotypes of older lesbians and gay men. Educational Gerontology, 35, 424-452. 


\section{Appendix A}

Please take a moment to answer the following questions about yourself.

Information from these questions is intended to help the researcher know your background and basic demographic information. All the information you provide will be kept confidential, and there is no need to identify yourself on this form. We remind you that participation is completely voluntary. Thank you for your willingness to participate!

Please circle one answer for each question:

1. Gender: male female transgender

2. Sexual orientation: heterosexual? Yes No

3. Age:

4. Ethnic heritage: African American

Hispanic/Mexican American

Asian American

Native American

Multi-Racial

White/Non-Hispanic/European American

Other

5. Religious affiliation:

6. Employment before retirement 


\section{Highest level of education:}

High School or less (up to Grade 12)

_ Trades School or Community College (Associate's Degree)

_ Some College (less than 4 years or no degree)

College Degree (Bachelor's or 4-year degree)

Graduate/Professional Degree (Master's Degree, Ph. D., M. D.,

Psy. D., or

other degree requiring graduate education)

\section{Relationship status:}

Single (never been married)

Married

Divorced

Separated

Widowed

Other 